\title{
LETTERS
}

\section{Electronic health records: physicians must lead}

Improving the electronic health record (EHR) is a cause that physician and nursing leaders must take on, because they are the only ones who stand to benefit.

There is no financial incentive for existing EHR companies to reinvent their products, and little interest on the part of medical administrators in new technologies that do not directly contribute to the financial bottom line. Neither can we depend on government health ministries, which are already receiving the aggregate data provided by current EHRs in order to manage the health care system.

Reading Dr. Robert Wachter's call for reimagining the EHR to take advantage of technology "without slavishly replicating the old paper-based ... workflow," ${ }^{1}$ I was reminded of Dr. Lawrence Weed's work in the 1970 s to promote the "problemoriented medical record" as an alternative to the standard practice of paper chart documentation. ${ }^{2}$ The problemoriented medical record was a superior system in concept, but it required computer technology (not available at that time) to be practical and efficient.

Recently, I led a team that created a practical EHR (konote.ca) based on Weed's problem-oriented concept. We enhanced the concept by integrating narrative and quantitative data in the same note, and adding data visualization tools that engage the patient. Early adopters are excited by the novelty, but these are clinicians - and the market reality is that clinicians do not buy these systems, administrators do.
Physicians must lead. I hope the Canadian Medical Association takes up the challenge.

\section{David Gotlib MD}

Psychiatrist, Toronto, Ont.

Cite as: CMAJ 2018 February 26;190:E228. doi: $10.1503 / \mathrm{cmaj} .68877$

\section{References}

1. Collier R. Electronic health records contributing to physician burnout. CMAJ 2017;189:E1405-6.

2. Weed LR. Medical records, medical education, and patient care: the problem-oriented record as a basic tool. Cleveland: Press of Case Western Reserve University [Distributed by Year Book Medical Publishers, Chicago]; 1970

Competing interests: David Gotlib developed KoNote, an electronic health record system mentioned in this letter. KoNote is a nonprofit venture. 